\title{
Nystagmus: A FRMD7 Prospective
}

Hafeez Ullah Khan', Muhammad Zakryya Khan ${ }^{2, *}$, Abdul Malik Tareen1, Muhammad Musawir Khan'

1Department of Microbiology, University of Balochistan, Quetta, Pakistan

2Department of Biological Science, International Islamic University, Islamabad, Pakistan

\section{A BSTRACT}

Nystagmus is involuntary up and down, to and fro and oscillatory movement of eye. Nystagmus is caused by different inheritance pattern, which can be; AD (autosomal dominant), AR (autosomal recessive) and X-linked. This review elaborates the mutational canvas of FRMD7 gene involved in X-linked Nystagmus. In Pakistan the publication is either not available or no research findings has been reported for FRMD7 gene according to our knowledge.

$\begin{array}{lll}\text { Keywords } & \text { *Address of Correspondence } & \text { Article info. } \\ \begin{array}{l}\text { Nystagmus, X-linked, FRMD7, mutations, } \\ \text { Pakistan. }\end{array} & \text { zakriabiotech@gmail.com } & \text { Received: April 22, 2019 } \\ \text { Accepted: July 8, 2019 }\end{array}$

Cite this article: Khan HU, Khan MZ, Tareen AM, Khan MM. Nystagmus: A FRMD7 Prospective. RADS J. Biol. Res. Appl. Sci. 2019; 10(1): 41-43.

This is an Open Access article distributed under the terms of the Creative Commons Attribution License

Funding Source: Nil

Conflict of Interest: Nil

(http://creativecommons.org/licenses/by/4.0), which permits unrestricted use, distribution, and reproduction in

any medium, provided the original work is properly cited.

\section{INTRODUCTION}

Nystagmus; the involuntary movement of eye, acquired in infancy or later in life, that results in limited or reduced vision. It is also called "Dancing eyes" due to this involuntary eye movement ${ }^{1}$. During normal situation head rotates around an axis and distant visual images are held by rotating the eyes in the opposite direction on the axis². The angular acceleration in the vestibule is sensed by the semicircular canal. These send massages to the nuclei, from here, then pass to the extraocular muscles to allow eye movement to fixate on one object along the head movement. When these canals are stimulated then eye condition is Nystagmus. The direction of ocular movement is related to the semicircular canal that is being stimulated ${ }^{3}$. It is revealed that 1 in 1,000-2,000 people are affected by congenital and acquired nystagmus ${ }^{4}$.

\section{FRMD7}

FRMD7 is associated with $x$-linked Idiopathic congenital nystagmus and reported by 5 previously known as LOC90167, on Xq26-q27. The function of FRMD7 is still unclear. The FRMD7 gene comprises 12 exons and 714- amino $a^{2}{ }^{5}$. According to HGMD professional more than 90 mutations has been reported in FRMD7.

\section{FRMD7 Mutations}

In different families from Italian, England, and German origin, Tarpey et al., 5 reported different (twenty two) mutations of FRMD7 gene in the families with congenital $X$-linked nystagmus. Thomas ${ }^{6}$ reported 3 novel mutations in FRMD7 gene. In another study Zhang ${ }^{7}$ reported in frame deletion on 3 base pair in first exon of the FRMD7 gene in Chinese family. Shiels ${ }^{8}$ reported mutation in the $6^{\text {th }}$ exon of FRMD7 gene resulting in amino acid change, leucine to arginine on 142 position. While analyzing Xlinked Turkish family with nystagmus, Kaplan ${ }^{9}$ reported mutation in FRMD7 $8^{\text {th }}$ exon, which resulted arginine to glycine on amino acid position 229 . He ${ }^{10}$ reported a deletion mutation of 2 base pair deletion in $12^{\text {th }}$ exon of FRMD7 in Chinese family. Thomas ${ }^{6}$ reported a leucine change into valine at 231 amino acid position in FRMD7 gene in X-linked nystagmus family. A splice site variant in the $11^{\text {th }}$ intron of the FRMD7 gene has been reported by ${ }^{11}$. 
Self12 reported novel mutation in FRMD7 gene with insertion of Adenine on 880 position (880insA) resulting extremely variable phenotype. In another study ${ }^{13}$ mutation analysis of the FRMD7 entire gene, A novel mutation (misses) is reported; $A>G$ at nucleotide position 917 (c. A917G), which resulting the amino acid change of Arg for GIn at 305 position. The mutation was homozygous and heterozygous for female, hemizygous for male in affected individuals. Kumar ${ }^{14}$ compared the clinical and oculomotor characteristics of albinism and FRMD7 associated Nystagmus and showed differences in characteristics between nystagmus with albinism. Pendular waveform types and nystagmus frequency were higher in FRMD7 as compared to albinism, whereas anomalous head posture and strabismus were lower in FRMD7. A study published of a novel mutation in the 12th exon of FRMD7 gene in Chinese family having four base pair deletion at CDNA position 1486-1489 (TTTT) ${ }^{15}$.

In another study 5 novel mutations identified in FRMD7 gene, at cDNA position 70,689, 782, 812, and 910 with $G>T$ AG deletion, $G>A, G>T$, and $C>t$, resulting in amino acid change of G24W, Ser232del, R260Q, C271F and R303X respectively ${ }^{16}$. In another similar study AlMoallem ${ }^{17}$, elaborated the mutation canvas of FRMD7 and expended mutation findings by reporting five novel mutation and 4 already reported. Novel includes; a frame shift mutation cDNA position at 2036 deletion occurred, missense mutation at position $801 \mathrm{C}$ changed into $\mathrm{A}$, a spice-site mutation of 5 plus of c.497 G>A and a $1.29 \mathrm{Mb}$ deletion.

\section{FRMD7 Mutation in Pakistan}

In Pakistan very limited study is performed for the Nystagmus. No sufficient study evidence has been found in Pakistan for FRMD7. A wide study is needed to elaborate the mutational canvas of the FRMD7 mutation in Pakistan. Despite high consanguinity rate in Pakistan a lot of genetic disorders and their variants are reported but no sufficient published data is available to study or analyze the FRMD7 mutation prevalence in Pakistan.

\section{DISCUSSION}

Idiopathic congenital nystagmus is more common inherited eye disorder associated with Nystagmus, and individual affected with this disorder often have eye visual defects. It is X-linked condition and FRMD7 gene's mutations are responsible for Idiopathic congenital nystagmus ${ }^{7}$.

Idiopathic congenital nystagmus can cause different problems in eye and in most cases severely affect the vision and it is the most common eye disorder affecting visual acuity ${ }^{18}$. This condition is usually present in infancy or within 2 to 4 months of birth without other sensory complications $^{18}$.

The inheritance pattern of nystagmus is different in different cases; can be AD (Autosomal Dominant), AR (Autosomal Recessive) or x-linked. The x-linked nystagmus is considered to be most common.

Mutations in the FRMD7 gene is considered the major reason of $x$-linked nystagmus and this finding is being reported by number of research publication in recent times. In Pakistan, very limited research is done and extensive study should be taken to understand and extend the nystagmus prevalence and horizon in Pakistan.

\section{REFERENCES}

1. Zahn JR. Incidence and characteristics of voluntary nystagmus. Journal of Neurology, Neurosurgery \& Psychiatry. 1978;41(7):617-23.

2. Medline Plus. February 27,2013 . Retrieved 2012-1212

3. Saladin KS, Porth C. Anatomy \& physiology: the unity of form and function. New York: McGraw-Hill; 2010.

4. Nystagmus, Royal National Institute of Blid People (RNIB), 2010.

5. Tarpey P, Thomas S, Sarvananthan N, Mallya U, Lisgo $\mathrm{S}$, et al. Mutations in FRMD7, a newly identified member of the FERM family, cause X-linked idiopathic congenital nystagmus. Nature genetics. 2006;38(11):1242.

6. Thomas MG, Crosier M, Lindsay S, Kumar A, Thomas $\mathrm{S}$, et al. The clinical and molecular genetic features of idiopathic infantile periodic alternating nystagmus. Brain. 2011;134(3):892-902.

7. Zhang Q, Xiao X, Li S, Guo X. FRMD7 mutations in Chinese families with $X$-linked congenital motor nystagmus. Mol Vis. 2007;13:1375-8.

8. Shiels A, Bennett TM, Prince JB, Tychsen L. X-linked idiopathic infantile nystagmus associated with a missense mutation in FRMD7.

9. Kaplan Y, Vargel I, Kansu T, Akin B, Rohmann E, et al. Skewed $X$ inactivation in an $X$ linked nystagmus family resulted from a novel, p. R229G, missense 
mutation in the FRMD7 gene. British Journal of Ophthalmology. 2008;92(1):135-41.

10. He X, Gu F, Wang Z, Wang C, Tong Y, et al. A novel frameshift mutation in FRMD7 causing $X$-linked idiopathic congenital nystagmus. Genetic testing. 2008;12(4):607-13.

11. Khan AO, Shinwari J, Al-Sharif L, Khalil DS, Al Tassan N. Prolonged pursuit by optokinetic drum testing in asymptomatic female carriers of novel FRMD7 splice mutation c. 1050+ 5 G> A. Archives of Ophthalmology. 2011;129(7):936-40.

12. Self J, Lotery A. The molecular genetics of congenital idiopathic nystagmus. InSeminars in ophthalmology. Taylor \& Francis. 2006;21(2):87-90.

13. Radhakrishna U, Ratnamala U, Deutsch $S$, Bartoloni $L$, Kuracha MR, et al. Novel homozygous, heterozygous and hemizygous FRMD7 gene mutations segregated in the same consanguineous family with congenital $X$-linked nystagmus. European Journal of Human Genetics. 2012;20(10):1032.

14. Kumar A, Gottlob I, Mclean RJ, Thomas S, Thomas $M G$, et al. Clinical and oculomotor characteristics of albinism compared to FRMD7 associated infantile nystagmus. Investigative ophthalmology \& visual science. 2011;52(5):2306-13.

15. Du W, Bu J, Dong J, Jia Y, Li J, et al. A novel frameshift mutation in FRMD7 causes $X$-linked idiopathic congenital nystagmus in a Chinese family. Molecular vision. 2011;17:2765.

16. Li N, Wang L, Cui L, Zhang L, Dai S, et al. Five novel mutations of the FRMD7 gene in Chinese families with X-linked infantile nystagmus. Molecular vision. 2008;14:733.

17. AlMoallem B, Bauwens M, Walraedt S, Delbeke $P$, De Zaeytijd J, et al. Novel FRMD7 mutations and genomic rearrangement expand the molecular pathogenesis of $X$-linked idiopathic infantile nystagmus. Investigative ophthalmology \& visual science. 2015;56(3):1701-10.

18. Zhang $X$, Ge $X, Y u Y$, Zhang $Y$, Wu $Y$, et al. Identification of three novel mutations in the FRMD7 gene for X-linked idiopathic congenital nystagmus. Scientific reports. 2014; 4:3745. 